\title{
Increased cystatin $F$ levels correlate with decreased cytotoxicity of cytotoxic T cells
}

\author{
Mateja Prunk ${ }^{1,2}$, Milica Perisic Nanut ${ }^{1}$, Jerica Sabotic ${ }^{1}$, Urban Svajger ${ }^{3}$, Janko Kos ${ }^{1,2}$ \\ 1 Jožef Stefan Institute, Department of Biotechnology, Ljubljana, Slovenia \\ ${ }^{2}$ University of Ljubljana, Faculty of Pharmacy, Ljubljana, Slovenia \\ ${ }^{3}$ Blood Transfusion Centre of Slovenia, Ljubljana, Slovenia
}

Radiol Oncol 2019; 53(1): 57-68

Received 8 December 2018

Accepted 5 January 2019

Correspondence to: Prof. Janko Kos, Ph.D., Faculty of Pharmacy, University of Ljubljana, Aškerčeva cesta 7, SI-1000 Ljubljana, Slovenia. Phone: +386 14769 604; Fax: +386 14258 031; E-mail: janko.kos@ffa.uni-lj.si

Disclosure: No potential conflicts of interest were disclosed.

Background. Cystatin $\mathrm{F}$ is a protein inhibitor of cysteine peptidases, expressed predominantly in immune cells and localised in endosomal/lysosomal compartments. In cytotoxic immune cells cystatin F inhibits both the major progranzyme convertases, cathepsins $\mathrm{C}$ and $\mathrm{H}$ that activate granzymes, and cathepsin $\mathrm{L}$, that acts as perforin activator. Since perforin and granzymes are crucial molecules for target cell killing by cytotoxic lymphocytes, defects in the activation of either granzymes or perforin can affect their cytotoxic potential.

Materials and methods. Levels of cystatin F were assessed by western blot and interactions of cystatin $\mathrm{F}$ with cathepsins $\mathrm{C}, \mathrm{H}$ and $\mathrm{L}$ were analysed by immunoprecipitation and confocal microscopy. In TALL-104 cells specific activities of the cathepsins and granzyme B were determined using peptide substrates.

Results. Two models of reduced T cell cytotoxicity of TALL-104 cell line were established, either by treatment by ionomycin or by immunosuppressive transforming growth factor beta. Reduced cytotoxicity correlated with increased levels of cystatin $\mathrm{F}$ and with attenuated activities of cathepsins C, $\mathrm{H}$ and $\mathrm{L}$ and of granzyme B. Co-localisation of cystatin $\mathrm{F}$ and cathepsins $\mathrm{C}, \mathrm{H}$ and $\mathrm{L}$ and interactions between cystatin $\mathrm{F}$ and cathepsins $\mathrm{C}$ and $\mathrm{H}$ were demonstrated. Conclusions. Cystatin $\mathrm{F}$ is designated as a possible regulator of T cell cytotoxicity, similar to its role in natural killer cells.

Key words: cystatin F; cysteine cathepsins; TALL-104; TGFB; ionomycin; anergy

\section{Introduction}

The ability of cancer cells to avoid immune response is one of hallmarks of cancer ${ }^{1}$ and thus, several therapeutic approaches are aimed to enhance anticancer immunity. In cancer immunotherapy the activation and maintaining of $\mathrm{T}$ cells directed towards tumour antigens provided promising results. ${ }^{2}$ In this case the main players are CD8+ cytotoxic T lymphocytes (CTLs), major cell effectors of adaptive immunity, since they possess the ability to kill target cells directly. ${ }^{3}$ The key pathway employed by CTLs in target cell killing involves release of perforin and granzymes from cytotoxic granules. Perforin is a pore-forming protein that enables entry of granzymes into the target cell.
Perforin deficiency, or failure to deliver fully functional perforin due to its genetic mutations, leads to the fatal immunoregulatory disorder, familial hemophagocytic lymphohistiocytosis. ${ }^{4}$ Granzymes are a family of serine peptidases that, once in the target cell, trigger different cell death signalling pathways. In humans there are five granzymes, A, $\mathrm{B}, \mathrm{H}, \mathrm{K}$ and $\mathrm{M}$, among them granzymes $\mathrm{A}$ and $\mathrm{B}$ have established cytotoxic roles. Indeed, the cytotoxicity of CTLs in mice lacking granzymes A and $B$, even if they possess functional perforin and other granzymes, is greatly reduced. ${ }^{5}$ Granzyme B has the most potent pro-apoptotic role, since its activity to cleave after aspartate residues mimics the function of caspases. On the other hand, granzyme A cleaves substrates after basic residues and induces 
a slower type of cell death. In addition to different substrate specificity, both granzymes differ also in their potency; while nanomolar levels of granyzme $\mathrm{B}$ are cytotoxic, micromolar levels of granzyme A are needed for cytotoxicity. ${ }^{5}$

As well as perforin and granzymes, cytotoxic granules contain certain cysteine cathepsins. These comprise a group of 11 cysteine peptidases (cathepsins B, C, F, H, K, L, O, S, V, X and W) exhibiting different tissue distributions, cellular localisations, proteolytic activities and protein levels, all involved in a variety of physiological and pathological processes. In CTLs the most notable is the role of cathepsin C, which is responsible for the activation of pro-granzymes by removing an N-terminal dipeptide. ${ }^{6}$ However, cathepsin $\mathrm{C}$ null mice, while active granzyme $\mathrm{A}$ is completely $\mathrm{ab}$ sent, still possess active granzyme B in functional cytotoxic cells, and it has been shown that cathepsin $\mathrm{H}$ can act as an additional pro-granzyme convertase. ${ }^{7}$ Furthermore, cysteine cathepsins are implicated in the activation of perforin by cleaving its C-terminus. ${ }^{8,9}$ Thus, cathepsin L can cleave perforin, although redundancy with other peptidases has also been demonstrated. . $^{8,10}$

The activity of cysteine cathepsins is regulated by their endogenous protein inhibitors, the cystatins. In immune cells a notable role is attributed to cystatin $\mathrm{F}$, a tight-binding inhibitor of cysteine cathepsins and legumain, which has several features distinguishing it from other members of cystatins II family. First, it is synthesised predominantly in immune cells and its expression depends on their activation state or differentiation status. ${ }^{11-14}$ Secondly, it presents as a dimer, stabilized by disulphide bonds ${ }^{15}$ and as a dimer it does not inhibit cysteine cathepsins. ${ }^{16,17}$ Its monomerization can be facilitated by proteolytic cleavage of the 15 $\mathrm{N}$-terminal amino acids, however, this truncation significantly changes the inhibitory profile. ${ }^{18}$ While full-length monomeric cystatin $\mathrm{F}$ does not inhibit cathepsin $\mathrm{C}$, after $\mathrm{N}$-terminal truncation it becomes its potent inhibitor. ${ }^{18}$ Furthermore, cystatin $\mathrm{F}$ is, apart from cystatin $\mathrm{E} / \mathrm{M}$, the only cystatin that is glycosylated, a feature crucial for its endosomal/ lysosomal trafficking and internalisation..$^{19}$ Lastly, cystatin $\mathrm{F}$ can also function in trans, so that secreted cystatin $\mathrm{F}$ can be taken up by bystander cells and regulate the activity of cysteine cathepsins in the endosomal/lysosomal pathway. ${ }^{20,21}$

Cystatin F can regulate the cytotoxicity of natural killer (NK) cells by inhibiting the pro-granzyme convertases, cathepsins $\mathrm{C}$ and $\mathrm{H}$, and cathepsin $\mathrm{L}$ that is implicated in perforin processing. ${ }^{22,23}$ The result is lower activity of granzymes A and B and, consequently, lower cytotoxicity of $\mathrm{NK}$ cells. ${ }^{21}$ Cystatin $\mathrm{F}$ is therefore an upstream regulator of split anergy, an NK cell status in which cells lose their cytotoxicity but increase their expression and secretion of various cytokines. ${ }^{24,25} \mathrm{~A}$ similar anergic state was also described in CTLs, where anergy is defined as a hyporesponsive state that a lymphocyte can acquire after it encounters an antigen. ${ }^{26}$ The minimal requirement for a cell to be termed anergic is hypo- or un-responsiveness to at least one of its effector functions. ${ }^{27}$ However, even though the regulatory role of cystatin F in NK cells is well established, much less is known about its role in CTLs. Since both cell types share the same molecular machinery for target cell killing, cystatin F could affect CTL cytotoxicity. In fact, it has been shown that overexpression of cystatin $\mathrm{F}$ in mouse CTLs leads to lower activity of cathepsin C. In human CD8+ T cell blasts, cystatin F was found co-localised with granzyme A, perforin and LAMP- $1 .^{18}$ A role for cystatin $\mathrm{F}$ in regulating human CTL's cytotoxicity has, however, not yet been demonstrated.

We have investigated both the involvement of endogenous cystatin $\mathrm{F}$ in the inhibition of intracellular cathepsins $\mathrm{C}$ and $\mathrm{H}$ and its impact on the cytotoxicity of CTLs, using primary human CTLs and TALL-104 cells. Treatment with transforming growth factor $\beta$ (TGF $\beta$ ) and ionomycin were shown to induce anergy of TALL-104 cells, attenuating their cytotoxicity against both NK-sensitive K-562 cells and NK-resistant Raji cells. It was further shown that the attenuated cytotoxicity correlates with increased levels of cystatin $\mathrm{F}$ and decreased specific activities of cathepsins $\mathrm{C}, \mathrm{H}$ and $\mathrm{L}$ and granzyme $\mathrm{B}$. Our results thus designate cystatin $\mathrm{F}$ as a regulator of the cytotoxicity of CTLs.

\section{Materials and methods}

\section{Antibodies}

Rabbit anti-cystatin F antibody from Davids Biotechnologie $\mathrm{GmbH}$ (Regensburg, Germany) was used in all experiments except in western blots, where rabbit anti-cystatin $\mathrm{F}$ antibody from Sigma-Aldrich (St. Louis, MO, USA) was used. Mouse anti-cathepsin $C$ was from Santa Cruz Biotechnology (Santa Cruz, CA, USA). Other antibodies against human cathepsins were developed: 1D10 mouse anti-cathepsin $\mathrm{H}$ antibody ${ }^{28}$, sheep anti-cathepsin $\mathrm{H}^{28}$ and sheep anti-cathepsin L. ${ }^{29}$ Rabbit and mouse anti- $\beta$-actin antibodies 
were from Sigma-Aldrich, rabbit anti-glyceraldehyde 3-phosphate dehydrogenase (GAPDH) was from Santa Cruz Biotechnology and mouse antiGAPDH from Proteintech (Rosemont, IL, USA). Secondary anti-rabbit, anti-mouse and anti-sheep antibodies conjugated with horseradish peroxidase (HRP), were from Jackson Immuno Research (West Grove, PA, USA). Secondary anti-rabbit and anti-mouse antibodies conjugated with fluorescent dyes DyLight 650 and DyLight 550, respectively, were from Invitrogen (Carlsbad, CA, USA). For immunofluorescence studies all secondary antibodies were from Thermo Fisher Scientific (Thermo Scientific, Rockford, IL, USA): donkey anti-rabbit Alexa Fluor 488, goat anti-rabbit Alexa Fluor 647, donkey anti-mouse Alexa Fluor 555 and donkey anti-sheep Alexa Fluor 488.

\section{Cell culture and isolation}

TALL-104 cells (CRL-11386) (ATCC, Manassas, VA, USA) were cultured in IMDM medium (ATCC) with 20\% foetal bovine serum (Gibco, Carlsband, CA, USA), $100 \mathrm{IU} / \mathrm{ml}$ interleukin-2 (Bachem, Bubendorf, Switzerland), $2.5 \mu \mathrm{g} / \mathrm{ml}$ recombinant human albumin (Sigma-Aldrich) and $0.5 \mu \mathrm{g} / \mathrm{ml}$ D-mannitol (Sigma-Aldrich). TALL-104 cell line was used as a model of cytotoxic T lymphocytes since these cells express markers typical of a T-cell phenotype (CD2+, CD7+, CD3+, CD8+, $\mathrm{TCR} \alpha / \beta+)^{30}$, can kill NK-sensitive as well as NKresistant target cells and use primarily the perforin/granzyme pathway. ${ }^{31}$ K-562 (CCL-243) (ATCC) and Raji cells (CCL-86) (ATCC) were cultured in RPMI-1640 (Lonza) with 10\% foetal bovine serum, $100 \mathrm{U} / \mathrm{mL}$ penicillin (Lonza) and $100 \mathrm{U} / \mathrm{mL}$ streptomycin (Lonza). The same complete medium, but with $30 \mathrm{IU} / \mathrm{mL}$ interleukin-2, was used for primary human CD8+ T cells (pCTLs) that were isolated from buffy coats of healthy volunteers at the Blood Transfusion Centre of Slovenia, Republic of Slovenia, according to institutional guidelines. The National Medical Ethics Committee of the Ministry of Health, Republic of Slovenia, approved the study. Cytotoxic CD8+ T cells were isolated by negative selection magnetic beads kit (Miltenyi Biotech, Bergisch Glasbach, Germany), according to the manufacturer's protocol. The purity of pCTLs was determined by flow cytometry using fluorescence labelled antibodies against CD3, CD4, CD8, CD56, CD16, CD19 and TCR $\alpha / \beta$ (all from Miltenyi Biotech) and was always $>95 \%$. All cells were grown in a humidified incubator at $37^{\circ} \mathrm{C}$ in $5 \% \mathrm{CO}_{2}$.

\section{Cell activation, TGFB and ionomycin treatment}

TALL-104 and pCTLs were stimulated with antiCD3/anti-CD28 antibody coated beads (CD3/CD28 Dynabeads ${ }^{\circledR}$ human T-Activator, Thermo Fischer Scientific), a protocol that mimics the physiological activation of T-cells, since immobilised anti-CD3 antibody triggers signalling through T-cell receptor complex, while anti-CD28 antibody triggers the co-stimulatory signalling. ${ }^{32}$ Stimulation was performed according to manufacturer's instructions; beads were added to TALL-104 or pCTLs at a cell density of $10^{6} / \mathrm{mL}$ and at a bead to cell ratio of 1:1. Before stimulation, pCTLs were rested in the complete medium with interleukin-2 overnight. TALL-104 cells were treated with $100 \mathrm{pM}$ TGF $\beta$ (R\&D Systems, Minneapolis, MN, USA) for 24 hours in the presence or absence of anti-CD3/antiCD28 antibody coated beads in complete medium. For induction of anergy the cells were treated with $0.5 \mu \mathrm{M} \mathrm{Ca}^{2+}$ ionophore ionomycin (Santa Cruz) for $16 \mathrm{~h}$ in complete medium. After ionomycin treatment, cells were washed and either analysed or, to test if anergy is reversed after full activation, resuspended in fresh complete medium and activated. pCTLs were activated with anti-CD3/anti-CD28 antibody coated beads, while TALL-104 cells were activated with $1 \mu \mathrm{M}$ ionomycin and $10 \mathrm{nM}$ phorbol 12-myristate 13-acetate (PMA; Sigma-Aldrich), a stimulation protocol that similarly to stimulation with anti-CD3/anti-CD28 antibody coated beads mimics activation of the T-cell receptor, since ionomycin triggers signalling pathways of T-cell receptor, while PMA triggers signalling pathways of costimulatory molecules.

\section{Calcein-AM release assay}

The calcein-AM release assay ${ }^{33}$ was used for measuring TALL-104 cytotoxic activity. TALL-104 cells were used as effector cells and K-562 or Raji as target cells. First, the target cells were resuspended in serum-free RPMI and loaded with $15 \mu \mathrm{M}$ calceinAM (Sigma) for 30 minutes and after two washes in complete RPMI medium the cell density was adjusted to $10^{5} / \mathrm{ml}$. Wells of a U-bottom 96-well plate were preloaded with sufficient numbers of TALL-104 cells in $100 \mu \mathrm{L}$ of complete IMDM to produce the desired effector to target cell ratios (E:T). To measure spontaneous and total release of calcein-AM, wells were preloaded with $100 \mu \mathrm{L}$ of complete IMDM or $100 \mu \mathrm{L}$ of lysis buffer $(50 \mathrm{mM}$ sodium borate, $0.1 \%$ Triton $\mathrm{X}$ ), respectively. Assays 
were started by adding $5 \times 10^{3}$ target cells in $50 \mu \mathrm{L}$ of complete RPMI to each well. The plate was then centrifuged for 2 minutes at $200 \mathrm{x}$ g to enhance conjugate formation by amassing the cells at the bottom of the plate, then incubated for 4 hours in a humidified incubator at $37^{\circ} \mathrm{C}$ with $5 \% \mathrm{CO}_{2}$. After incubation the plate was centrifuged for 5 minutes at $700 \times$ g. $50 \mu \mathrm{L}$ of supernatant was then transferred to a new microtiter plate. Fluorescence of released calcein-AM was measured with a microplate reader (Tecan M1000) with $496 \mathrm{~nm}$ excitation and $516 \mathrm{~nm}$ emission filters. Fluorescence of each E:T ratio was measured in at least three replicate wells. Specific lysis (\%) was calculated as [(test release - spontaneous release)/(total release - spontaneous release) $x$ 100]. Lytic units (LU30/106 cells) were determined by using the inverse of the number of effector cells needed to lyse $30 \%$ of target cells $\times 100 .{ }^{34}$ To investigate the requirement for extracellular $\mathrm{Ca}^{2+}$, the cytotoxicity assay was performed in the presence of 2 mM EGTA and $1 \mathrm{mM} \mathrm{Mg}^{2+}$. Excess $\mathrm{Ca}^{2+}$ was added at $2 \mathrm{mM}$ concentration.

\section{Cell death analysis by Annexin V-FITC/ propidium iodide double-staining}

Cell death was assessed using an FITC-conjugated Annexin V/propidium iodide kit (Apoptosis detection kit, Beckton Dickinson, Franklin Lakes, NJ, USA), according to the manufacturer's protocol. Stained cells were examined by flow cytometry (FACS Calibur, Beckton Dickinson) using Cell Quest pro software (Beckton Dickinson). A minimum of twenty thousand cells were analysed per sample.

\section{Preparation of whole cell lysates}

Cells were first washed in PBS then lysed in lysis buffer. For western blot analysis, cell lysis buffer (50 mM Tris- $\mathrm{HCl} \mathrm{pH} 8,150 \mathrm{mM} \mathrm{NaCl}, 1 \%$ Triton X-100, $0.5 \%$ sodium deoxycholate, $0.1 \%$ SDS and $1 \mathrm{mM}$ EDTA) with addition of protease inhibitors (Roche) was used. For the activity assay of cathepsins $0.1 \mathrm{M}$ citrate buffer $\mathrm{pH} 6.2$ with $1 \%$ Triton X-100 lysis buffer was used, while the lysis buffer for granzyme B activity was $25 \mathrm{mM}$ HEPES, 250 $\mathrm{mM} \mathrm{NaCl}, 2.5 \mathrm{mM}$ EDTA, $0.1 \%$ Nonident p-40, $\mathrm{pH}$ 7.4. Cell lysates were incubated on ice for 30 minutes then centrifuged at $16,000 \times \mathrm{g}$ for $20 \mathrm{~min}-$ utes at $4^{\circ} \mathrm{C}$. Supernatants were transferred to fresh tubes and protein concentration determined using the DC-Protein Assay Kit (Bio-Rad Laboratories, Hercules, CA, USA).

\section{Western blot}

Samples containing 30 to $50 \mu$ g of cell lysates' total protein were heated for 10 minutes at $100^{\circ} \mathrm{C}$ in either non-reducing or reducing $(40 \mathrm{mM}$ dithiothreitol) loading buffer, resolved in SDS-PAGE and transferred onto a nitrocellulose membrane (GE Healthcare, Chicago, IL, USA) using wet transfer at $200 \mathrm{~mA}$ for 90 minutes. Membranes were blocked in $5 \%$ non-fat dry milk in PBS (cystatin F) or 5\% non-fat dry milk in tris-buffered saline (TBS) with 0.1\% Tween-20 (for cathepsins C, H and L and granzyme B) for 1 hour at room temperature. Primary antibodies were diluted in blocking solution and incubated overnight at $4^{\circ} \mathrm{C}$. After washing with PBS or TBS with $0.1 \%$ Tween-20 the membranes were incubated with HRP-conjugated secondary antibodies or in the dark with fluorescently labelled secondary antibodies (anti-rabbit-DyLight 650 or anti-mouse-DyLight 550) in blocking solution. Membranes with HRP-conjugated antibodies were incubated with Lumi-Light western blotting substrate (Roche). Images were acquired using a ChemiDoc MP System (Bio-Rad) and quantification analysis was performed in Image Lab, version 5.1 software (Bio-Rad).

\section{Confocal immunofluorescence microscopy and proximity ligation assay}

Cells were washed in PBS and left to adhere to microscope slides for 30 minutes at $37^{\circ} \mathrm{C}$. The slides were then fixed with $4 \%$ paraformaldehyde in PBS for 20 minutes, permeabilized with $0.1 \%$ Triton X-100 in PBS for 10 minutes and blocked with 3\% BSA (Sigma-Aldrich) in PBS for 30 minutes. Primary antibodies were diluted in $1 \%$ BSA in PBS and incubated for 90 minutes. Fluorescence labelled secondary antibodies were diluted in PBS and incubated for 1 hour. Slides were mounted with Prolong Gold Antifade Mountant containing $4^{\prime}, 6^{\prime}$-diamidino-2-phenylindole (DAPI) (Thermo Scientific). Control samples were run in the absence of one or both primary antibodies. Images were taken with a Carl Zeiss LSM 710 confocal microscope (Carl Zeiss, Oberkochen, Germany) with ZEN 2011 image software (Carl Zeiss).

For proximity ligation assay (PLA), after incubation with primary antibodies, PLA was performed according to the manufacturer's protocol (Olink Bioscience, Uppsala, Sweden). Briefly, for a single recognition experiment for cystatin $\mathrm{F}$, anti-rabbit PLUS and anti-rabbit MINUS were used as PLA probes, and the PLA probes anti-rabbit PLUS and 
anti-mouse MINUS for cystatin F-cathepsin C interaction. PLA probes were diluted in $1 \%$ BSA in PBS and incubated for 1 hour at $37^{\circ} \mathrm{C}$. Ligation and amplification were performed using Detection Reagents Red. Coverslips were mounted on glass slides using Duolink In Situ Mounting Medium with DAPI. Controls were run in the absence of one or both primary antibodies. A cystatin F single recognition experiment was performed as a positive control. Fluorescence microscopy, using a Carl Zeiss LSM 710 confocal microscope, and high resolution images $(63 \times 1.4 \mathrm{NA})$ of at least 100 cells per condition were acquired. Cell images were exported using ZEN 2012 SP1 (black edition) version 8.1 software (Carl Zeiss) in TIF format for further analysis and signal quantification in Blobfinder 3.2 software (Centre for Image Analysis, Uppsala University, Uppsala, Sweden).

\section{Immunoprecipitation}

TALL-104 cells were washed once in PBS and lysed in ice-cold lysis buffer $(50 \mathrm{mM}$ Tris- $\mathrm{HCl} \mathrm{pH}$ 7.4, $100 \mathrm{mM} \mathrm{NaCl}, 0.25 \%$ Triton X-100, with protease inhibitors (Roche)). After incubation on ice for 30 minutes, lysates were centrifuged at 16,000 x $\mathrm{g}$ for 20 minutes and supernatants were transferred into fresh tubes. Dynabeads protein G (Thermo Scientific) were coated with either rabbit anti-cystatin F antibody (Davids Biotechnologie) or an antibody raised against lectin isolated from Macrolepiota procera (BioGenes $\mathrm{GmbH}$, Berlin, Germany), as a negative control. Dynabeads protein $\mathrm{G}$ with bound antibodies was then added to lysates. After rotation at $4^{\circ} \mathrm{C}$ overnight, beads were washed three times with lysis buffer and boiled for 10 minutes in $1 \times$ SDS loading buffer. Eluted proteins were analysed by western blot.

\section{Determination of enzyme activities}

Enzyme activities were determined using specific fluorogenic substrates: $70 \mu \mathrm{M}$ H-Gly-Phe-7-amino4-methylcoumarin (AMC) (Bachem) for cathepsin C, $20 \mu \mathrm{M}$ H-Arg-AMC (Bachem) for cathepsin $\mathrm{H}$, $50 \mu \mathrm{M}$ Z-Phe-Arg-AMC for cathepsin L (Bachem) and $50 \mu \mathrm{M}$ acetyl-Ile-Glu-Pro-Asp-AMC for granzyme B (Bachem). The assay buffers used were $25 \mathrm{mM}$ MES, $100 \mathrm{mM} \mathrm{NaCl}, 5 \mathrm{mM}$ cysteine, $\mathrm{pH}$ 6 for cathepsin C, $100 \mathrm{mM}$ MES, 2mM EDTA, 5 $\mathrm{mM}$ cysteine, $\mathrm{pH} 6.5$ for cathepsins $\mathrm{H}$ and $\mathrm{L}$ and $50 \mathrm{mM}$ Tris- $\mathrm{HCl}, 100 \mathrm{mM} \mathrm{NaCl}, \mathrm{pH} 7.4$ for granzyme B. Whole-cell lysates were first activated in assay buffer for 15 minutes at room temperature

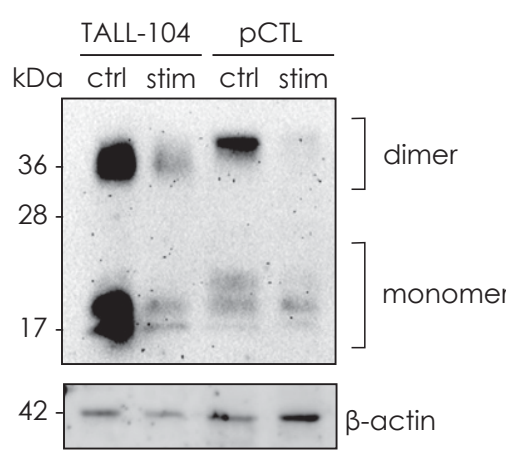

(A)

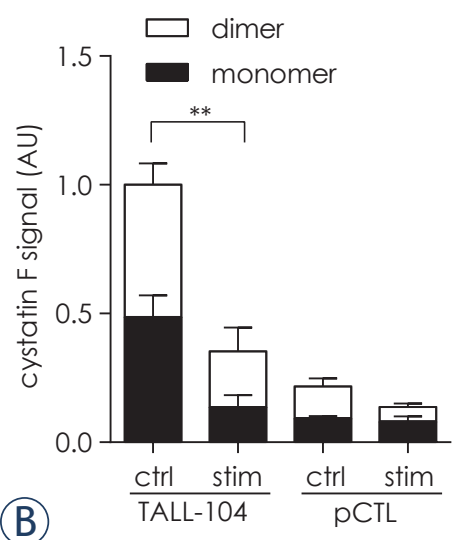

FIGURE 1. Expression of cystatin F in TALL-104 cells and human CD8+ T cells. (A) Representative western blot experiment showing expression of the monomeric and dimeric form of cystatin F in unstimulated and stimulated TALL-104 cells and human CD8+ T cells. Both, TALL-104 and human CD8+ T cells, were stimulated with anti-CD3/anti-CD28 antibody coated beads. Multiple bands correspond to differently glycosylated forms of cystatin F.21 (B) Quantification of western blot data was performed in Image Lab software. Signals for cystatin F were first normalized to $\beta$-actin signal and TALL-104 control sample intensity was set to 1 arbitrary unit (AU). Relative intensities of other bands were calculated accordingly. Error bars represent s.e.m between three separate experiments.

** $\mathrm{p} \leq 0.01$, statistical analysis was performed for total cystatin $\mathrm{F}$ levels.

ctrl = control; $\mathrm{PCTL}=$ primary human cytotoxic $\mathrm{T}$ cells: stim = stimulated;

for cathepsins or for 30 minutes at $37^{\circ} \mathrm{C}$ for granzyme B. The substrate was then added and formation of fluorescent degradation products was measured continuously with excitation at $370 \mathrm{~nm}$ and emission at $460 \mathrm{~nm}$ on a microplate reader Infinite M1000 (Tecan, Männedorf, Switzerland). To determine cathepsin L activity, $5 \mu \mathrm{M}$ irreversible inhibitor of cathepsin B, CA-074 (Bachem), was added before the addition of substrate. The rate of AMC release was calculated and normalised to the enzyme protein levels determined from western blot. The activity of the control sample was set to $100 \%$ and activities of other samples were adjusted accordingly.

\section{Statistical analyses}

Data were analysed using GraphPad Prism 6 (GraphPad Software, San Diego, CA, USA). Differences between groups were analysed with the $t$ test when two groups were compared or with one-way ANOVA followed by Šidák's multiple comparisons test to assess which groups differed significantly when more than two groups were compared. Differences were accepted as significant when $\mathrm{p} \leq 0.05$. 


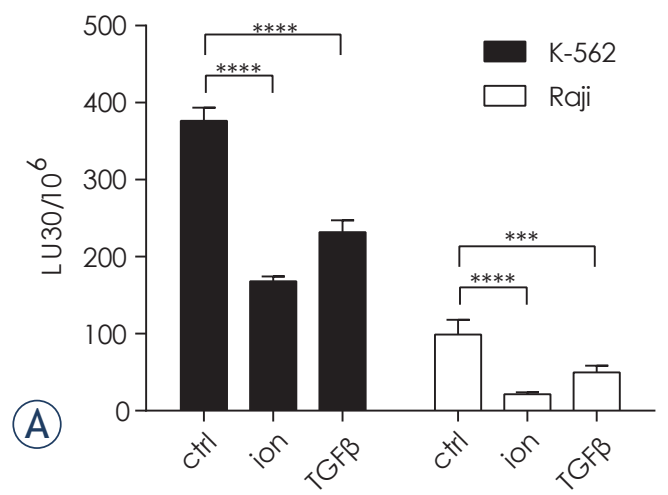

K-562
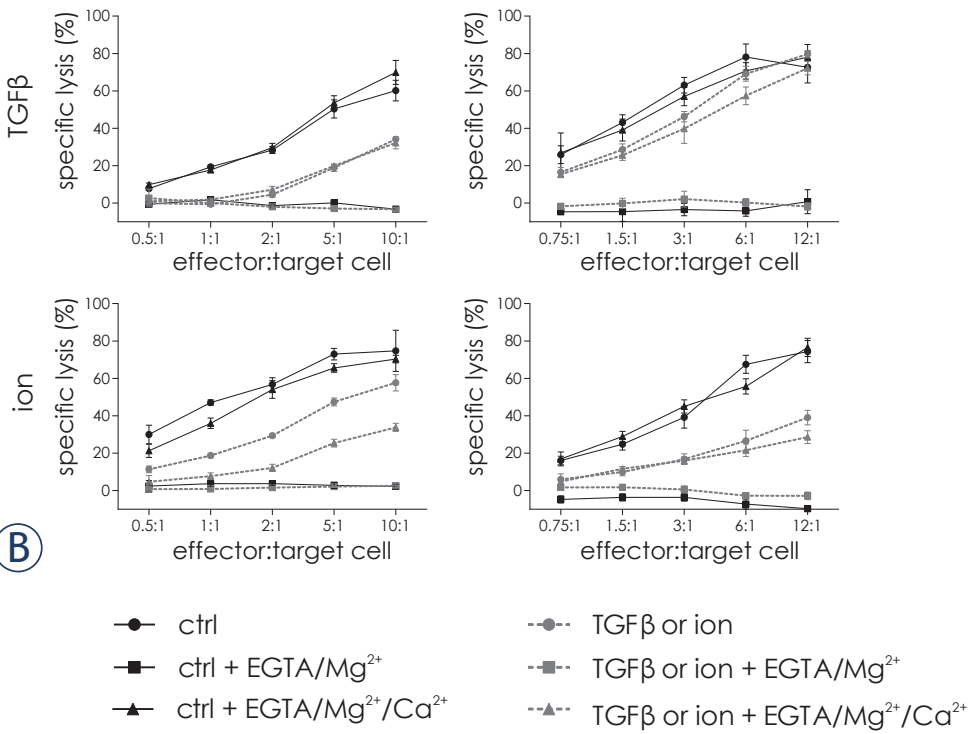

FIGURE 2. Cytotoxicity of TALL-104 after TGF $\beta$ or ionomycin treatment is reduced. (A) TALL-104 cells were treated with 100 PM TGF $\beta$ for 24 hours or $0.5 \mu \mathrm{M}$ ionomycin for 16 hours. Cytotoxicity against NK-sensitive targets K-562 cells and NK-resistant targets Raji cells was measured by a 4 hour calcein-AM release assay at different effectorto-target cell ratios. Lytic units (LU 30/106) were calculated using the inverse number of TALL-104 cells needed to lyse $30 \%$ of target cells $\times 100$. Error bars represent SD between triplicates. ANOVA was used for statistical analysis, ${ }^{* * *} p \leq 0.001$ and ${ }^{* * * *} p \leq$ 0.0001 . (B) Cytotoxicity of control, TGF $\beta$ and ionomycin treated TALL-104 cells against K-562 and Raji target cells was measured by a 4 hour calcein-AM release assay at different effector-to-target cell ratio. During the assay the $\mathrm{Ca}^{2+}$ chelator EGTA or EGTA with excess $\mathrm{Ca}^{2+}$ was added. Error bars represent SD between triplicates.

\section{Results}

\section{Cystatin F is expressed in TALL-104 and in human primary CD8+ T cells}

Expression of cystatin F in TALL-104 cells and in human primary CD8+ $\mathrm{T}$ cells (pCTLs) isolated from peripheral blood mononuclear cells of healthy donors was examined by western blot. Both cell types expressed cystatin $\mathrm{F}$ but at a higher level in TALL-104. Stimulation of cells with anti-CD3/antiCD28 antibody coated beads led to a decrease in both monomeric and dimeric forms of cystatin $\mathrm{F}$ (Figure 1).

\section{Cytotoxicity is decreased and cystatin $F$ levels increased in response to TGFB and ionomycin}

Since TGF $\beta$ has been reported to target the effector function of CTLs by transcriptional repression of perforin and granzymes ${ }^{35}$, we determined whether TALL-104 cytotoxic function is affected by TGF $\beta$. After TGF $\beta$ treatment, the cytotoxicity of TALL-104 cells against NK-sensitive targets, i.e. K-562 cells, as well as against NK-resistant Raji cells, tested by calcein-AM release assay, was significantly reduced (Figure 2A). The killing of target cells was completely inhibited by the addition of $\mathrm{Ca}^{2+}$ chelating agent EGTA to the assay medium, while addition of excess $\mathrm{Ca}^{2+}$ restored the cytotoxic function (Figure 2B), implying that the loss of cytotoxic function was due to the $\mathrm{Ca}^{2+}$ chelating action of EGTA. Furthermore, we confirmed, by double staining of cells with annexin V-FITC and propidium iodide, that TGF $\beta$ treatment did not induce cell death of TALL-104 cells. More than 97\% of both control and TGF $\beta$ treated cells were negative for both markers of cell death, excluding cell death as the cause of the lower cytotoxicity.

Further, ionomycin was used to induce the anergy and decrease the cytotoxicity of TALL-104 cells. TALL-104 cells treated with low concentrations of ionomycin displayed a marked decrease in cytotoxicity against K-562 and Raji targets (Figure 2A) and, like that with TGF $\beta$, the addition of EGTA during the calcein-AM release assay completely abrogated the cytotoxicity, while addition of excess $\mathrm{Ca}^{2+}$ restored the cytotoxic activity, confirming the involvement of the granzyme/perforin pathway in cell cytotoxicity (Figure 2B). Propidium iodide staining confirmed that ionomycin treatment does not trigger cell death in TALL-104 and pCTLs (data not shown).

Levels of cystatin F in cell lysates were further assessed by western blot. In TALL-104 cells, total cystatin $\mathrm{F}$ levels increased after treatment with TGF $\beta$ (Figure 3A,B) or with ionomycin (Figure 3C,D). In TGF $\beta$ treated TALL-104 cells the increase of total cystatin $F$ levels was due to an increase of the active monomeric form, while the dimeric form, that does not inhibit cysteine cathepsins, was decreased. Ionomycin treatment on the other hand triggered an increase of both monomeric and dimeric forms. 
Both control and ionomycin treated TALL-104 cells were stimulated with PMA/ionomycin, which decreased cystatin F levels (Figure 3D). Nevertheless, in ionomycin treated cells stimulated with PMA/ ionomycin cystatin $\mathrm{F}$ levels remained higher compared to the control TALL-104 cells stimulated with PMA/ionomycin (Figure 3D). Similarly, in pCTLs cystatin $\mathrm{F}$ levels were increased after ionomycin treatment in both, unstimulated cells and following stimulation with anti-CD3/anti-CD28 beads.

\section{Cysteine cathepsins $\mathrm{C}, \mathrm{H}$ and $\mathrm{L}$ are expressed in TALL-104 cells and in human CD8+ T cells and co-localise with cystatin $\mathrm{F}$}

It has been postulated that, in NK cells, the most prominent targets of cystatin $\mathrm{F}$ are cathepsins $\mathrm{C}$ and $\mathrm{H}$, that act as pro-granzyme convertase ${ }^{21}$, and cathepsin L, that is implicated in perforin processing. ${ }^{10,21}$ In this study, both pCTLs and TALL-104 cells were found to express cathepsins $\mathrm{C}, \mathrm{H}$ and $\mathrm{L}$ (Figure 4A-C). Using confocal microscopy, cystatin F was shown to be co-localised with cathepsins C, $\mathrm{H}$ and L in TALL-104 cells (Figure 4D) and pCTLs (Figure 4E). Co-localisation of cystatin F with cathepsins $\mathrm{C}$ and $\mathrm{H}$ was confirmed by co-immunoprecipitation (Figure $4 \mathrm{~F}$ ) and with cathepsin $\mathrm{C}$ by proximity ligation assay (Figure 4G).

\section{Increased cystatin F levels are correlated with decreased specific activities of cathepsins $\mathrm{C}, \mathrm{H}$ and $\mathrm{L}$ and of granzyme B}

We further studied, using specific substrates and whole cell lysates, whether cystatin $\mathrm{F}$ can affect enzymatic activities of cathepsins $\mathrm{C}, \mathrm{H}$ and $\mathrm{L}$ in TALL-104 cells (Figure 5). Activities of cathepsins $\mathrm{C}, \mathrm{H}$ and $\mathrm{L}$ were significantly decreased in ionomycin treated TALL-104 cells and, after stimulation with PMA/ionomycin, their activity remained significantly decreased (Figure 5A-C). Similarly, activities of cathepsins $C$ and $L$ were significantly decreased in TGF $\beta$ treated TALL-104 cells both unstimulated and stimulated with anti-CD3/ anti-CD28 antibody coated beads (Figure 5E,G). However, cathepsin $\mathrm{H}$ activity was decreased in TGF $\beta$ treated TALL-104 cells stimulated with antiCD3/anti-CD28 antibody coated beads, but not in unstimulated cells (Figure 5F).

It was next determined as to whether lower cathepsins $\mathrm{C}$ and $\mathrm{H}$ activities result in lower granzyme B activities. Indeed, in ionomycin treated

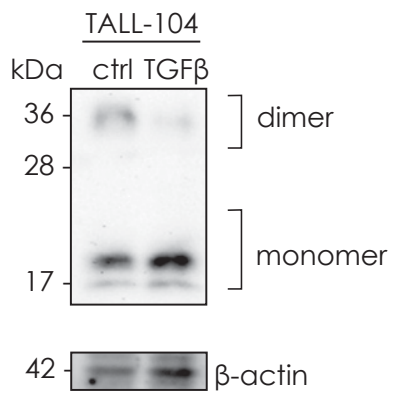

(A)
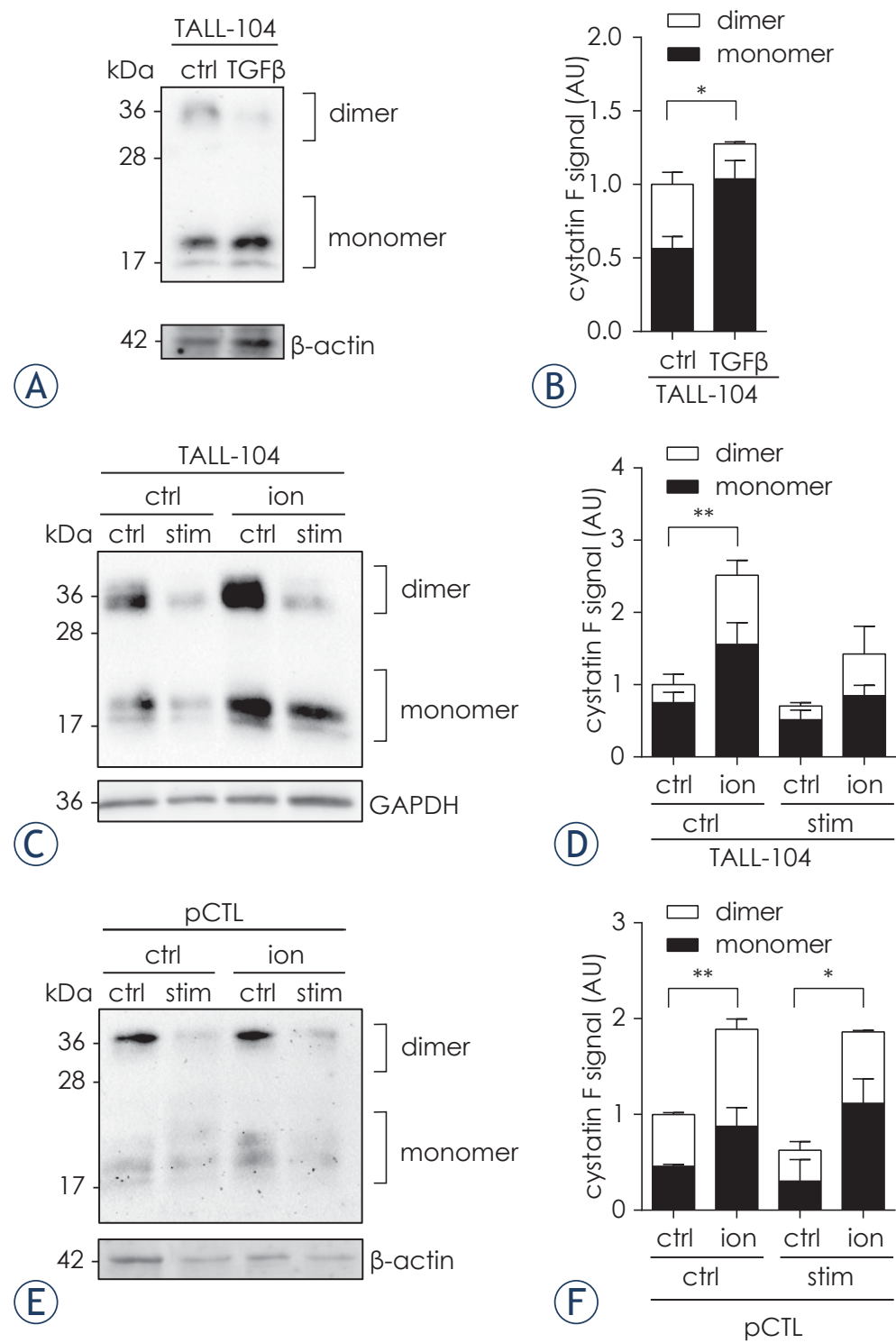

FIGURE 3. TGF $\beta$ and ionomycin increase cystatin F protein levels. (A, B) TALL-104 cells were stimulated with anti-CD3/anti-CD28 antibody coated beads in the presence or absence of $100 \mathrm{pM}$ TGFB. (C, D) TALL-104 cells were treated with $0.5 \mu \mathrm{M}$ ionomycin for 16 hours and stimulated with $10 \mathrm{nM}$ PMA and $1 \mu \mathrm{M}$ ionomycin. $(E, F)$ Human CD8+ T cells were treated with $0.5 \mu \mathrm{M}$ ionomycin for 16 hours and stimulated with anti-CD3/anti-CD28 antibody coated beads. (A, C, E) show representative western blots for cystatin F, while (B, D, F) show quantification of $3(B, D)$ or $2(F)$ independent experiments. Quantification was performed in Image Lab software. Signals for cystatin F were first normalized to $\beta$-actin (B, F) or GAPDH (D) signal and TALL-104 control sample intensity was set to 1 arbitrary unit (AU). Relative intensities of other bands were calculated accordingly. Data are presented as mean \pm s.e.m. ${ }^{*} p \leq 0.05$, ${ }^{* *} p \leq 0.01$, statistical analysis was performed for total cystatin $\mathrm{F}$ levels.

$\mathrm{ctrl}=$ control; ion = ionomycin; $\mathrm{pCTL}=$ primary human cytotoxic $\mathrm{T}$ cells; stim = stimulated

TALL-104 cells and in unstimulated TGF $\beta$ treated TALL-104 cells the granzyme $B$ activity was significantly reduced (Figure 5D), while in TGF $\beta$ treated TALL-104 cells stimulated with anti-CD3/anti- 
(A)
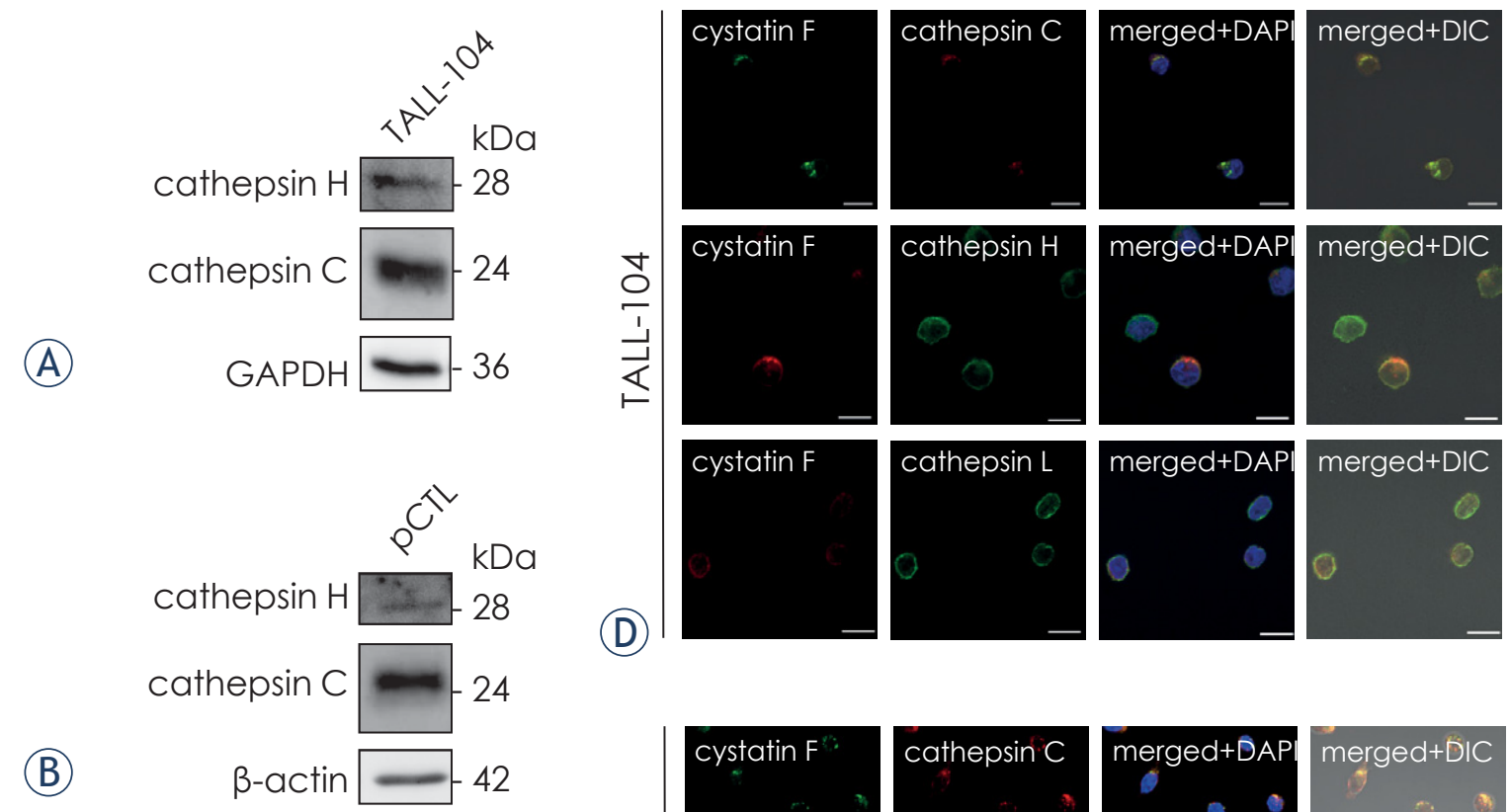

(D)
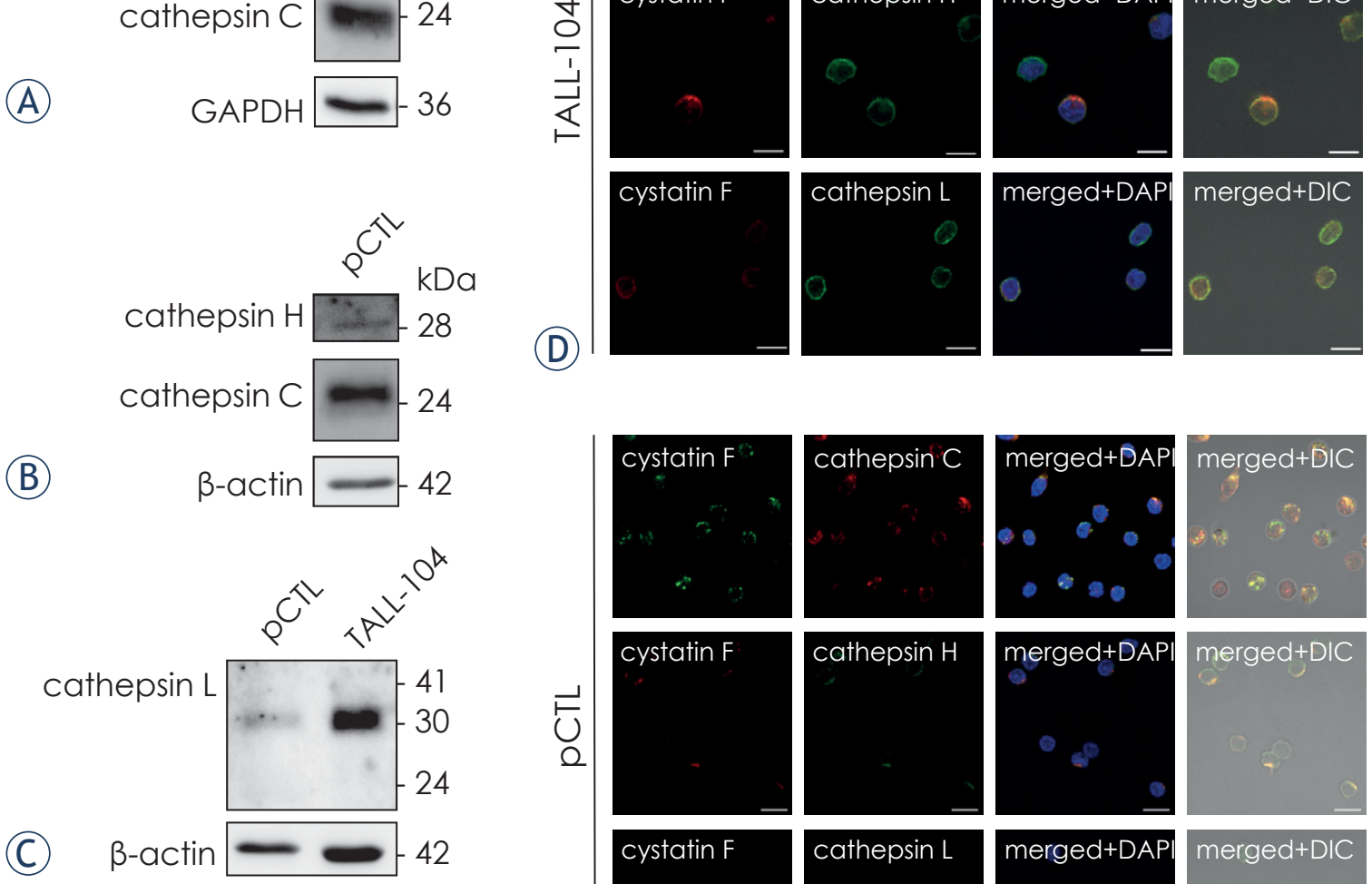

(C)

$\beta-a c t i n$
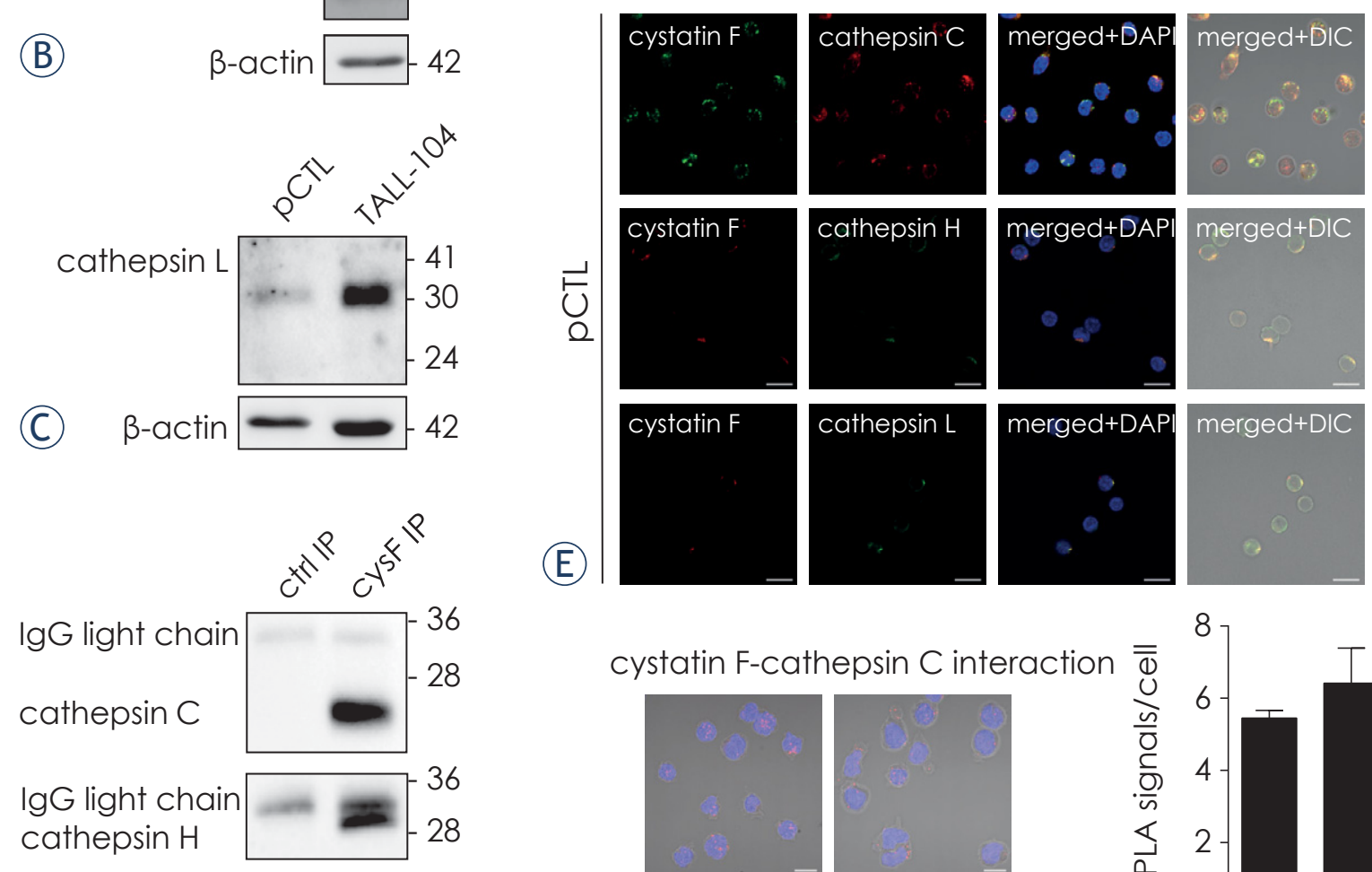

(F)

$$
\text { TALL-104 }
$$

(E)
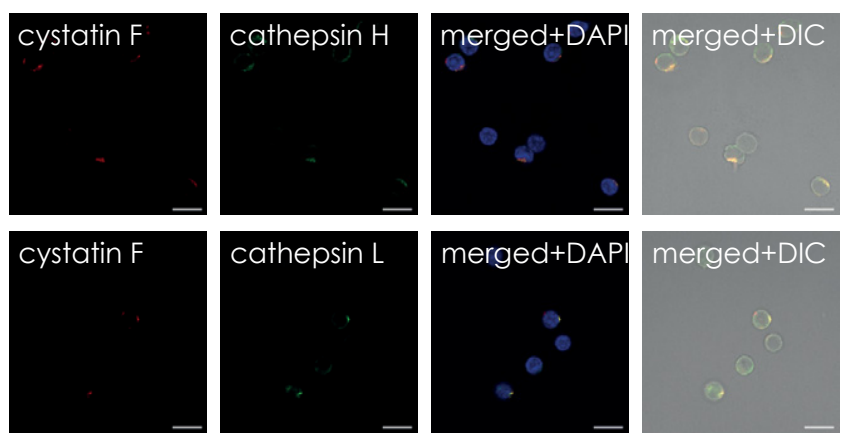

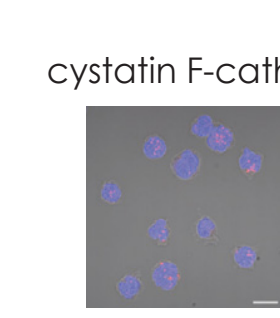

(G)

TALL-104

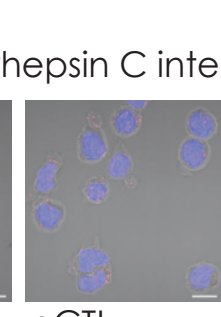

PCTL

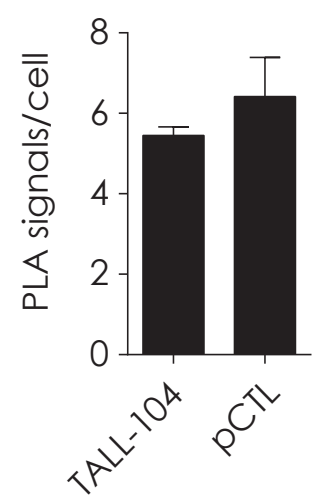

FIGURE 4. Expression of cathepsins C, H and L in TALL-104 cells and human CD8+ T cells and their co-localisation with cystatin F. (A-C) TALL-104 and PCTLs were analysed for cathepsins C, H and L expression by western blot. GAPDH or $\beta$-actin staining was used to show protein loading. (D, E) Co-localisation of cystatin F with cathepsins $C, H$ and $L$ was studied by immunofluorescence microscopy in TALL-104 (D) and PCTLs (E). Cystatin F (green) and cathepsin C (red) co-localisation is shown in first row, cystatin $\mathrm{F}$ (red) and cathepsin $\mathrm{H}$ (green) in second row and cystatin F (red) and cathepsin L (green) in third row. Bars represent $10 \mu \mathrm{m}$. (F) TALL-104 cell lysates were immunoprecipitated with cystatin F antibody and analysed by western blot with anti-cathepsin C and $\mathrm{H}$ antibodies. (G) Proximity ligation experiment for cystatin F-cathepsin C interaction in TALL-104 cells and pCTLs. Signals were quantified in BlobFinder software. Bars represent $10 \mu \mathrm{m}$. 
(A)

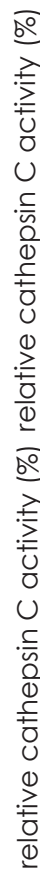

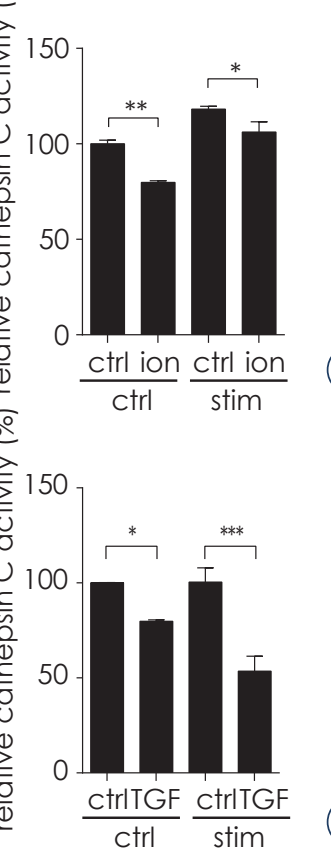

(B) $\frac{2}{2}$

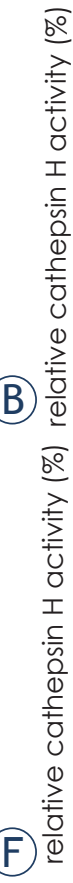

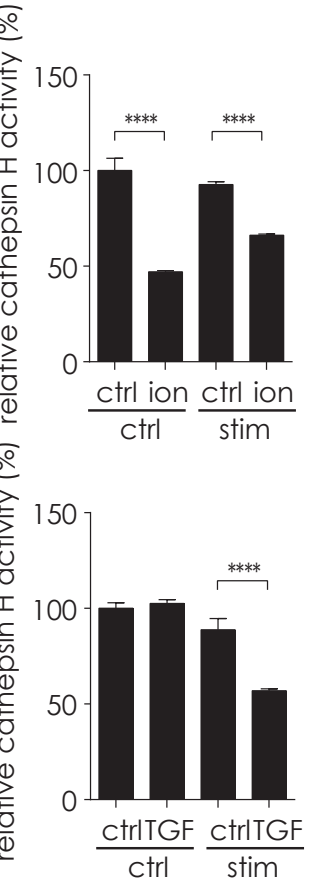
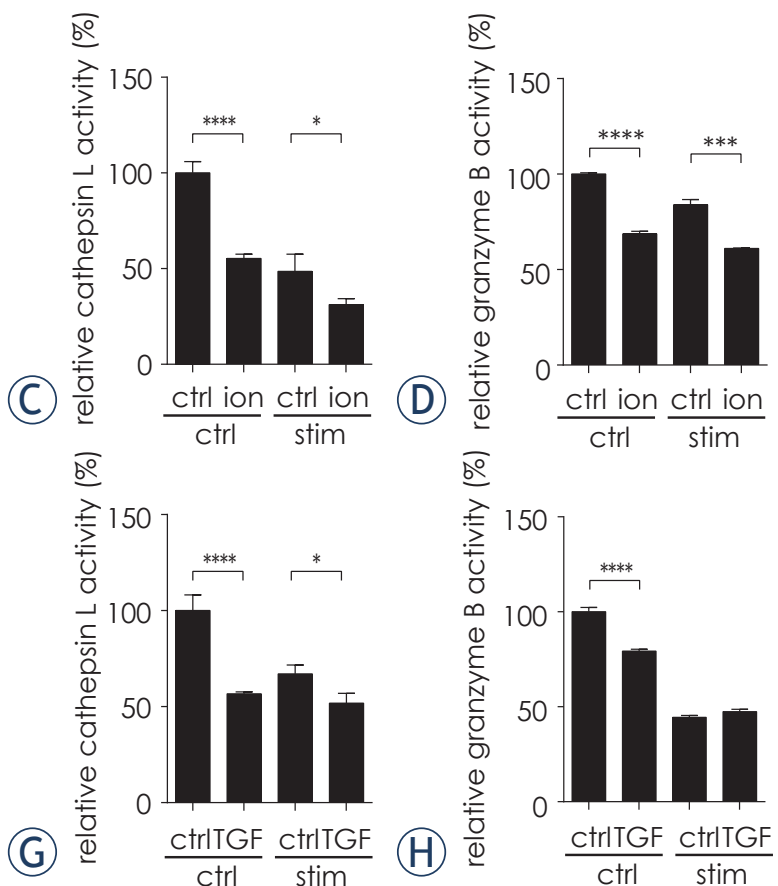

FIGURE 5. Activities of cathepsins C, H and L and granzyme B in TALL-104 cells. Activities of cathepsins C (A, E), H (B,F), L (C,G) and granzyme B (D, H) in TALL-104 whole cell lysates after TGFB or ionomycin treatment. Error bars represent SD between triplicates. ${ }^{*} \mathrm{P}$ $\leq 0.05,{ }^{* *} p \leq 0.01,{ }^{* * *} p \leq 0.001$ and ${ }^{* * *} p \leq 0.0001$.

ctrl = control; ion = ionomycin; stim = stimulated; TGF = transforming growth factor beta

CD3/anti-CD28 antibody coated beads granzyme B activity was not decreased (Figure $5 \mathrm{H}$ ).

\section{Discussion}

Cystatin $\mathrm{F}$ has recently been shown to be an upstream regulator of split anergy in NK cells, where it inhibits cathepsins $\mathrm{C}$ and $\mathrm{H}$, major pro-granzyme convertases, resulting in reduced cytotoxicity of NK cells. ${ }^{21,34}$ Even if NK cells and CTLs differ greatly in their mechanisms of target cell recognition and activation, the molecular mechanism, i.e. granule dependent cytotoxicity, that they exploit to trigger cell death is very similar. Therefore, we hypothesised that cystatin $\mathrm{F}$ could also be involved in regulating the cytotoxicity of CTLs. It has already been shown that, in mouse CTLs, overexpressed cystatin $\mathrm{F}$ decreases cathepsin $\mathrm{C}$ activity and that, in human CTLs, it is co-localised with granzyme $\mathrm{A}$ and perforin ${ }^{18}$ and granzyme $\mathrm{B}$ (unpublished observation). The ability of cystatin $\mathrm{F}$ to regulate the cytotoxicity of CTLs had not, however, been addressed before. Here we demonstrate that increased levels of cystatin $\mathrm{F}$ correlate with lower specific activities of cathepsins $\mathrm{C}, \mathrm{H}$ and $\mathrm{L}$ and granzyme B and, consequently, with the decreased cytotoxicity of CTLs.

First, the expression of cystatin $\mathrm{F}$ in primary human CTLs and the TALL-104 cell line was demonstrated by western blot (Figure 1) and found to be significantly higher in TALL-104 than in CTLs. On stimulation with anti-CD3/anti-CD28 antibody coated beads, cystatin F levels were decreased in both cell types. Changes in cystatin F levels following stimulation have been reported and were dependent on cell type and stimulation agents. Similarly to our findings, the differentiation of U937 and HL-60 cells with PMA caused a decrease in dimeric and monomeric forms of cystatin F. ${ }^{11,36}$ On the other hand, in monocyte-derived dendritic cells stimulated with toll-like receptor 3 ligand (polyinosinic:polycytidylic acid) or toll-like receptor 4 ligand (lipopolysaccharide), cystatin $\mathrm{F}$ levels were increased..$^{18}$ As in primary human NK cells, stimulation with interleukin-2 led to increased levels of the dimeric cystatin $\mathrm{F}$, while those of the monomeric form remained unchanged..$^{21,34}$

Secondly, TALL-104 cells were found to be less cytotoxic after treatment with either TGF $\beta$ or ionomycin (Figure 2). TGF $\beta$ is an immunosuppressive cytokine present in large amounts in tumour mi- 
croenvironment, its source being the cancer cells themselves or various cells of stromal and tumourinfiltrating cells. ${ }^{37}$ TGF $\beta$ plural: roles in cancer, notably suppressing the anti-cancer immune response by its inhibitory action on T cell proliferation, activation and effector functions. ${ }^{38}$ Indeed, it has been demonstrated that TGF $\beta$ directly inhibits the effector function of CTLs by inhibiting expression of perforin, granzymes $\mathrm{A}$ and $\mathrm{B}$, interferon-gamma and Fas ligand. ${ }^{35}$ In accordance with this, TGF $\beta$ was shown here to decrease TALL-104 cytotoxicity against NK-sensitive as well as NK-resistant target cells (Figure 2). Furthermore, cytotoxicity is completely inhibited by addition of the $\mathrm{Ca}^{2+}$ chelating agent EGTA, indicating that the $\mathrm{Ca}^{2+}$-dependent perforin/granzyme pathway is responsible for cytotoxicity in the setting of the present assay. This finding could be relevant for patient treatment, since TALL-104 cells have already been used in Phase I clinical trials on patients with refractory metastatic breast cancer ${ }^{39}$ and peritoneal carcinosis $^{40}$ and are currently in Phase II clinical trial in patients with ovarian carcinoma. ${ }^{41}$

The effect of TGF $\beta$ on TALL-104 cells is comparable to that of ionomycin, a compound known to trigger $\mathrm{T}$ cell anergy. ${ }^{26,42}$ Ionomycin triggers activation of $\mathrm{Ca}^{2+}$ /calcineurin signalling and activation of transcription factor NFAT. Because co-stimulation is absent, the PKC/IKK/Ras/MAP kinase arm is not activated and, consequently, activation of NFAT cooperating transcription factor AP1 is absent, leading to transcription of anergy associated genes. ${ }^{42,43}$ Interestingly, in ionomycin induced anergic CD4+ $T$ cells, cystatin $F$ was shown to be among the genes that were strongly induced.$^{42}$ In this study we demonstrated that, in TALL-104 cells, ionomycin triggers a hyporesponsive state characterised by their reduced ability to kill target cells (Figure 2). In both models of reduced cell cytotoxicity we consistently found increased levels of active monomeric cystatin F (Figure 3). This is in accordance with our previous results where active monomeric form of cystatin $\mathrm{F}$ was increased in split anergic NK cells. ${ }^{34}$ Split anergic NK cells, after interaction with NKsensitive targets, lose their cytotoxicity but still proliferate and secrete higher levels of cytokines..$^{25}$

Among the possible peptidases that could be inhibited by cystatin F, we focused on cathepsins $\mathrm{C}, \mathrm{H}$ and $\mathrm{L}$, since these are involved in the activation of effector molecules of the perforin/granzyme pathway. In previous studies it was shown that cystatin $\mathrm{F}$ is co-localised with cathepsins $\mathrm{C}$ and $\mathrm{H}$ in the same vesicles in NK-92 cells ${ }^{34}$ and with granzyme A and perforin in human CD8+ T cell blasts. ${ }^{18}$ Here, by immunofluorescence staining, we report the co-localisation of cystatin $\mathrm{F}$ with cathepsin C in primary human CTLs and TALL-104 cells and confirm its interaction with proximity ligation assay and co-immunoprecipitation (Figure 4). Furthermore, we have shown that cystatin F co-localizes and co-immunoprecipitates with cathepsin $\mathrm{H}$, confirming that cystatin $\mathrm{F}$ interacts with both major pro-granzyme convertases (Figure 4). With regard to cathepsin L, in PMA/ionomycin stimulated CD8+ T cells obtained from NOD mice, cathepsin L activity was observed..$^{44}$ In accordance with these results we detected cathepsin L protein in human CTLs and TALL-104 cells. Furthermore, we showed that cathepsin L co-localises with cystatin $\mathrm{F}$ in both cell types (Figure 4).

Increased expression of monomeric cystatin $\mathrm{F}$ in anergic and TGF $\beta$ treated TALL-104 cells was expected to have an impact on cathepsins' activity. Indeed, after treating TALL-104 cells with ionomycin, a significant drop in the specific activities of cathepsins $\mathrm{C}, \mathrm{H}$ and $\mathrm{L}$ was observed in both unstimulated and stimulated TALL-104 cells (Figure 5). With TGF $\beta$ the effect was similar for cathepsins $\mathrm{C}$ and $\mathrm{L}$, but less evident for cathepsin $\mathrm{H}$ (Figure 5). Given that cathepsins $\mathrm{C}$ and $\mathrm{H}$ are pro-granzyme $\mathrm{B}$ convertases, decreased levels of cathepsins $\mathrm{C}$ and $\mathrm{H}$ should affect the processing of granzymes from their precursor forms. In ionomycin treated TALL-104 cells this impact on granzyme $B$ activity was evident, whereas in TGF $\beta$ treated TALL-104 cells this was the case in unstimulated TALL-104 cells. However, in stimulated TALL-104 cells, granzyme B activity was not affected. It is possible that the combination of TGF $\beta$ treatment and stimulation with anti-CD3/anti-CD28 antibody coated beads triggers upregulation of an additional activating peptidase that compensates for the decreased activities of cathepsins $\mathrm{C}$ and $\mathrm{H}$. Indeed, in activated lymphocytes from mice lacking either cathepsin $\mathrm{C}$ or both cathepsins $\mathrm{C}$ and $\mathrm{H}$, granzyme A activity was absent, but there was still granzyme $B$ activity and it was suggested, similarly to our results, that an additional granzyme B convertase is present. $^{7}$

To conclude, it has been demonstrated that induction of a hyporesponsive state in CTLs, either by the immunosuppressive cytokine TGF $\beta$ or by ionomycin, correlates with decreased specific activities of cathepsins $\mathrm{C}$ and $\mathrm{H}$ and of their substrate, granzyme B. At the same time the expression of cystatin $\mathrm{F}$, an inhibitor of cysteine cathepsins, is increased, suggesting that cystatin $\mathrm{F}$ could be a negative regulator of the cytotoxicity of CTLs. Additional stud- 
ies, including silencing of cystatin F in CTLs and in vivo studies using mice lacking cystatin $\mathrm{F}$, would be needed to demonstrate unequivocally the role of cystatin F in CTLs and its potential as a target to improve the immunotherapy of cancer.

\section{Acknowledgement}

This work was supported by the Slovenian Research Agency [grant numbers P4-0127 and J46811 to JK].

Authors thank prof. Roger Pain for critical reading of the manuscript.

\section{References}

1. Hanahan D, Weinberg RA. Hallmarks of cancer: the next generation. Cell 2011; 144: 646-74. doi: 10.1016/j.cell.2011.02.013

2. Durgeau A, Virk $Y$, Corgnac $S$, Mami-Chouaib F. Recent advances in targeting CD8 T-cell immunity for more effective cancer immunotherapy. Front Immunol 2018; 9: 14. doi: 10.3389/fimmu.2018.00014

3. Trapani JA, Smyth MJ. Functional significance of the perforin/granzyme cell death pathway. Nat Rev Immunol 2002; 2: 735-47. doi: 10.1038/nri911

4. Voskoboinik I, Trapani JA. Perforinopathy: a spectrum of human immune disease caused by defective perforin delivery or function. Front Immunol 2013; 4: 441. doi: 10.3389/fimmu.2013.00441

5. Voskoboinik I, Whisstock JC, Trapani JA. Perforin and granzymes: function, dysfunction and human pathology. Nat Rev Immunol 2015; 15: 388-400. doi: $10.1038 /$ nri3839

6. Sutton VR, Waterhouse NJ, Browne KA, Sedelies K, Ciccone A, Anthony D, et al. Residual active granzyme $B$ in cathepsin C-null lymphocytes is sufficient for perforin-dependent target cell apoptosis. J Cell Biol 2007; 176: 425-33. doi: $10.1083 /$ jcb.200609077

7. D'Angelo ME, Bird PI, Peters C, Reinheckel T, Trapani JA, Sutton VR. Cathepsin $\mathrm{H}$ is an additional convertase of pro-granzyme B. J Biol Chem 2010; 285: 20514-9. doi: 10.1074/jbc.M109.094573

8. House IG, House CM, Brennan AJ, Gilan O, Dawson MA, Whisstock JC, et al. Regulation of perforin activation and pre-synaptic toxicity through C-terminal glycosylation. EMBO Rep 2017; 18: 1775-85. doi: 10.15252/ embr.201744351

9. Uellner R, Zvelebil MJ, Hopkins J, Jones J, MacDougall LK, Morgan BP, et al. Perforin is activated by a proteolytic cleavage during biosynthesis which reveals a phospholipid-binding C2 domain. EMBO J 1997; 16: 7287-96. doi: 10.1093/emboj/16.24.7287

10. Konjar S, Sutton VR, Hoves S, Repnik U, Yagita H, Reinheckel T, et al. Human and mouse perforin are processed in part through cleavage by the lysosomal cysteine proteinase cathepsin L. Immunology 2010; 131: 257-67. doi: 10.1111/j.1365-2567.2010.03299.x

11. Dautović $E$, Perišić Nanut $M$, Softić $A$, Kos J. The transcription factor $C /$ EBP $\alpha$ controls the role of cystatin $\mathrm{F}$ during the differentiation of monocytes to macrophages. Eur J Cell Biol 2018; 97: 463-73. doi: 10.1016/j. ejcb.2018.07.002

12. Halfon S, Ford J, Foster J, Dowling L, Lucian L, Sterling M, et al. Leukocystatin, A New Class II cystatin expressed selectively by hematopoietic cells. J Biol Chem 1998; 273: 16400-8. doi: 10.1074/jbc.273.26.16400

13. Magister S, Kos J. Cystatins in immune system. J Cancer 2013; 4: 45-56. doi: 10.7150/jca.5044

14. Ni J, Fernandez MA, Danielsson L, Chillakuru RA, Zhang J, Grubb A, et al. Cystatin $\mathrm{F}$ is a glycosylated human low molecular weight cysteine proteinase inhibitor. J Biol Chem 1998; 273: 24797-804. doi: 10.1074/jbc.273.38.24797
15. Cappello F, Gatti E, Camossetto V, David A, Lelouard H, Pierre P. Cystatin $F$ is secreted, but artificial modification of its C-terminus can induce its endocytic targeting. Exp Cell Res 2004; 297: 607-18. doi: 10.1016/j. yexcr.2004.03.048

16. Langerholc T, Zavasnik-Bergant V, Turk B, Turk V, Abrahamson M, Kos J. Inhibitory properties of cystatin $\mathrm{F}$ and its localization in U937 promonocyte cells. FEBS J 2005; 272: 1535-45. doi: 10.1111/j.1742-4658.2005.04594.x

17. Schüttelkopf AW, Hamilton G, Watts C, van Aalten DMF. Structural basis of reduction-dependent activation of human cystatin F. J Biol Chem 2006; 281: 16570-5. doi: 10.1074/jbc.M601033200

18. Hamilton G, Colbert JD, Schuettelkopf AW, Watts C. Cystatin F is a cathepsin C-directed protease inhibitor regulated by proteolysis. EMBO J 2008; 27: 499-508. doi: 10.1038/sj.emboj.7601979

19. Colbert JD, Plechanovová A, Watts C. Glycosylation directs targeting and activation of cystatin $\mathrm{F}$ from intracellular and extracellular sources. Traffic 2009; 10: 425-37. doi: 10.1111/j.1600-0854.2009.00881.x

20. Colbert JD, Matthews SP, Kos J, Watts C. Internalization of exogenous cystatin $\mathrm{F}$ supresses cysteine proteases and induces the accumulation of single-chain cathepsin L by multiple mechanisms. J Biol Chem 2011; 286: 42082-90. doi: 10.1074/jbc.M111.253914

21. Perišić Nanut $M$, Sabotič J, Švajger U, Jewett $A$, Kos J. Cystatin F affects natural killer cell cytotoxicity. Front Immunol 2017; 8: 1459. doi: 10.3389/ fimmu.2017.01459

22. Kos J, Nanut MP, Prunk M, Sabotič J, Dautović E, Jewett A. Cystatin F as a regulator of immune cell cytotoxicity. Cancer Immunol Immunother 2018. 67: 1931-8. doi: 10.1007/s00262-018-2165-5

23. Perišić Nanut M, Sabotič J, Jewett A, Kos J. Cysteine cathepsins as regulators of the cytotoxicity of NK and T cells. Front Immunol 2014; 5: 616. doi: 10.3389/fimmu.2014.00616

24. Jewett A, Bonavida B. Target-induced anergy of natural killer cytotoxic function is restricted to the NK-target conjugate subset. Cell Immunol 1995; 160: 91-7. doi: 10.1016/0008-8749(95)80013-9

25. Jewett A, Tseng $\mathrm{H}-\mathrm{C}$. Tumor induced inactivation of natural killer cell cytotoxic function; implication in growth, expansion and differentiation of cancer stem cells. J Cancer 2011; 2: 443-57. doi: 10.7150/jca.2.443

26. Choi S, Schwartz RH. Molecular mechanisms for adaptive tolerance and other T cell anergy models. Semin Immunol 2007; 19: 140-52. doi: 10.1016/j. smim.2007.02.005

27. Schwartz RH. Models of T cell anergy: is there a common molecular mechanism? J Exp Med 1996; 184: 1-8. doi: 10.1084/jem.184.1.1

28. Schweiger A, Stabuc B, Popovíc T, Turk V, Kos J. Enzyme-linked immunosorbent assay for the detection of total cathepsin $\mathrm{H}$ in human tissue cytosols and sera. J Immunol Methods 1997; 201: 165-72. doi: 10.1016/S00221759(96)00218-9

29. Kos J, Stabuc B, Schweiger A, Krasovec M, Cimerman N, Kopitar-Jerala N, et al. Cathepsins $B, H$, and $L$ and their inhibitors stefin $A$ and cystatin $C$ in sera of melanoma patients. Clin Cancer Res 1997; 3: 1815-22.

30. O'Connor R, Cesano A, Lange B, Finan J, Nowell PC, Clark SC, et al. Growth factor requirements of childhood acute T-lymphoblastic leukemia: correlation between presence of chromosomal abnormalities and ability to grow permanently in vitro. Blood 1991; 77: 1534-45.

31. Cesano A, Santoli D. Two unique human leukemic T-cell lines endowed with a stable cytotoxic function and a different spectrum of target reactivity analysis and modulation of their lytic mechanisms. In Vitro Cell Dev Biol 1992; 28A: 648-56.

32. Li Y, Kurlander RJ. Comparison of anti-CD3 and anti-CD28-coated beads with soluble anti-CD3 for expanding human T cells: differing impact on CD8 T cell phenotype and responsiveness to restimulation. J Transl Med 2010; 8: 104. doi: 10.1186/1479-5876-8-104.

33. Lichtenfels $R$, Biddison WE, Schulz $H$, Vogt AB, Martin R. CARE-LASS (calceinrelease-assay), an improved fluorescence-based test system to measure cytotoxic T lymphocyte activity. J Immunol Methods 1994; 172: 227-39. doi: 10.1016/0022-1759(94)90110-4

34. Magister S, Tseng H-C, Bui VT, Kos J, Jewett A. Regulation of split anergy in natural killer cells by inhibition of cathepsins $\mathrm{C}$ and $\mathrm{H}$ and cystatin $\mathrm{F}$. Oncotarget 2015; 6: 22310-27. doi: 10.18632/oncotarget.4208 
35. Thomas DA, Massagué J. TGF-beta directly targets cytotoxic T cell functions during tumor evasion of immune surveillance. Cancer Cell 2005; 8: 369-80. doi: 10.1016/j.ccr.2005.10.012

36. Nathanson C-M, Wassélius J, Wallin H, Abrahamson M. Regulated expression and intracellular localization of cystatin $\mathrm{F}$ in human U937 cells. Eur J Biochem 2002; 269: 5502-11. doi: 10.1046/j.1432-1033.2002.03252.x

37. Massagué J. TGFbeta in cancer. Cell 2008; 134: 215-30. doi: 10.1016/j. cell.2008.07.00

38. Dahmani A, Delisle J-S. TGF- $\beta$ in T Cell Biology: Implications for cancer immunotherapy. Cancers 2018; 10. doi: 10.3390/cancers10060194

39. Visonneau S, Cesano A, Porter DL, Luger SL, Schuchter L, Kamoun M, et al Phase I trial of TALL-104 cells in patients with refractory metastatic breast cancer. Clin Cancer Res 2000; 6: 1744-54.

40. Bengala C, Rasini V, Sternieri R, Dominici M, Andreotti A, Gelmini R, et al. Phase I study of intraperitoneal MHC unrestricted adoptive cell therapy with TALL-104 cells in patients with peritoneal carcinosis. J Clin Oncol 2007; 25: 3054-3054. doi: 10.1200/jco.2007.25.18_suppl.3054

41. Conte PF, Accoto M, Nannipieri F, Baretta Z, Baldoni A, Bonanno L, et al. Phase II trial of intraperitoneal (IP) MHC unrestricted adoptive cell therapy with TALL-104 cells in patients with ovarian carcinoma (OC) with minimal or microscopic residual disease at second look laparotomy/laparoscopy. Ann Oncol 2015; 26: viii10-viii11. doi: 10.1093/annonc/mdv514.21

42. Macián F, García-Cózar F, Im S-H, Horton HF, Byrne MC, Rao A. Transcriptional mechanisms underlying lymphocyte tolerance. Cell 2002; 109: 719-31. doi: 10.1016/S0092-8674(02)00767-5

43. Martinez GJ, Pereira RM, Äijö T, Kim EY, Marangoni F, Pipkin ME, et al. The transcription factor NFAT promotes exhaustion of activated $\mathrm{CD} 8^{+} \mathrm{T}$ cells. Immunity 2015; 42: 265-78. doi: 10.1016/j.immuni.2015.01.006

44. Yamada A, Ishimaru N, Arakaki R, Katunuma N, Hayashi Y. Cathepsin L inhibition prevents murine autoimmune diabetes via suppression of $\mathrm{CD} 8+\mathrm{T}$ cell activity. PLOS ONE 2010; 5. doi: 10.1371/journal.pone.0012894 